\title{
1. Editorial
}

2. Voces de nuestros

lectores

3. Ventanas abiertas a Pedagogía Universitaria

La Investigación en la PUCMM:

por Nelson de Jesús Gil

La investigación profesoral es logro de la excelencia.

por Guillermo van der Linde 11

4. Ecos desde las Facultades

La investigación formativa:

una alternativa promovida.

la Especialidad en Pedagogía

Universitaria de la PUCMM

por Rosa María Cifuentes

Derecho de las Tecnologías de la Información y Comunicación en la Universidad:

por Darie Súrestigar !

por Dariel Suárez

Universitaria es un espacio abierto que pretende colaborar con la formación permanente de los docentes en el área pedagógica, proporcionándoles lecturas, reflexiones $y$ testimonios que xum ayuden a renovarse $y$ actulizarse personal y profesionalmente.

Se agradece la divulgación para fines formativos. Los puntos de vista de los autores no expresan necesarmente apinín desariaConsejos Editorial y Asesor.
Proceso de normalización de una

la PUCMM
por Berta Tavares Hernández $\mathbf{2 1}$

5. Pasos y Huellas

Entrevista a Sarah González de Interinstitucionales, de

Investigación e Innovación de la
PUCMM

Entrevista a Radhamés Mejía

Director del Centro de Investiga-

ciones en Educación y Desarrollo

Humano (CIEDHUMANO), de la

6. Notas Bibliográficas

Comentario del libro Introducción

a la Investigación cualitativa de

a la Investigaci
Uwe Flick.

por Francisco D' Oleo

7. Cómics para Emilio prueba psicométrica en el Departamento de Orientación de Lora, Vicerrectora de Relaciones
Cuaderno de Pedagogía Universitaria Año 4 - Número 7 Enero - Junio 2007 ISSN 1814-4144

Directora General

Ana Margarita Haché de Yunén Directora Ejecutiva: Marta Vicente de Sánchez Consejo Editorial: Carmen Pérez Valerio Rosario Olivo de Regalado Rosario Olvo de Regala do uz Eneida Rodríguez Consejo Asesor Guillermo van der Linde José Joaquin Zouain

Diseño y Diagramación Griselidi García Quezada Impresión

Impresora Editora Teófilo, S. A

Cuaderno de Pedagogía Universitaria es stral de la Pontificia Universidad Católica Madre y Maestra coordinada por su Centro de Desarrollo Profesoral.

Los artículos son indizados en la Red Latinoamericana de Información y Roctmentación en Educación (REDUC) través de Centro de Doc (REDUC) a Investiga Centro de Documentación e Investigación Educativa (CEDIE), de la Biblioteca Central de la PUCMM.

Producción del Centro de Desarrollo Profesoral Pontificia Universidad Católica Madre y Maestra Autopista Durte Km. 1 \% , Santo, República Dominicana Teléfono: 809-580-1962. Extensiones: 315 y 316 http://www.pucmmsti.edu.do E- mail: cuaderno@pucmmsti.edu.do
Docencia, investigación y servicio constituyen los tres pilares que sostienen a las instituciones de educación superior prácticamente desde su origen. Sin importar e modelo de universidad que se tenga en la actualidad, nadie discute el binomio universidad-investigación.

Sin embargo, en el caso dominicano, la investigación ha sido una dimensión que no se ha desarrollado con la misma fortaleza y prioridad que la docencia. Podríamos calificarla, sin temor a equivocarnos, como la cenicienta, la gran ausente en el mundo de la Educación Superior. En este sentido, las universidades dominicanas tienen ante sí un gran reto si aspiran a ser parte de un mundo que se encuentra en el camino de la sociedad de la información y del conocimiento. Este desafío requiere de una toma de conciencia y de una organización de la actividad científica desde todos los ámbitos. Se necesita una reflexión sobre el tipo de conocimientos que demanda un país con altos índices de pobreza; urge re-dimensionar la investigación desde todas las instancias universitarias. Recordemos que la investigación se desarrolla y fructifica con la voluntad institucional, fundamentada en recursos financieros y humanos para las actividades de ciencia y tecnología.

Por supuesto que, como argumenta Guillermo van der Linde, el profesorado y su quehacer investigativo es uno de los engranajes clave en la consecución de este objetivo. La creación de un régimen de incentivos para promover esta actividad profesoral se constituye en una urgencia para aquellas universidades que tienen la excelencia como lema. Esta política implica también la formación de docentes a hivel de la investigación cuantitativa y cualitativa, pues ésta última posee en la actualidad un rol preponderante, como nos muestra Francisco D'Oleo en su reseña del libro Introducción a la investigación cualitativa.

Cabe destacar que la PUCMM realiza sus mejores esfuerzos para revitalizar su tradición investigativa, tal como escribe Nelson Gil y lo confirma la recién creada Vicerrectoría de Investigación e Innovación. Las entrevistas a Sarah González y Radhamés de las vivencias en torno al desarrollo de la investigación formativa con docentes en la Especialidad en Pedagogía Universitaria de la PUCMM. En estos momentos, un departamento como el de Orientación hace uso de la investigación para mejorar sus servicios estudiantiles.

Es un hecho que nuestra Institución cuenta con docentes, departamentos y centros de investigación que honran la producción de saberes. El CEUR, el CETT, el CUEPS son muestras de ello. No obstante, es vital que en cada facultad se piense en áreas que urge profundizar. Sigamos, por ejemplo, el llamado del profesor Darie Suárez, quien busca concienciar sobre la necesidad de promover la investigación en el ámbito del Derecho de las Tecnologías de la Información y la Comunicación. Nuestro profesorado debe, pues, detectar las áreas que ameritan la generación de nuevos conocimientos y actuar en consecuencia, con el apoyo de la Institución.
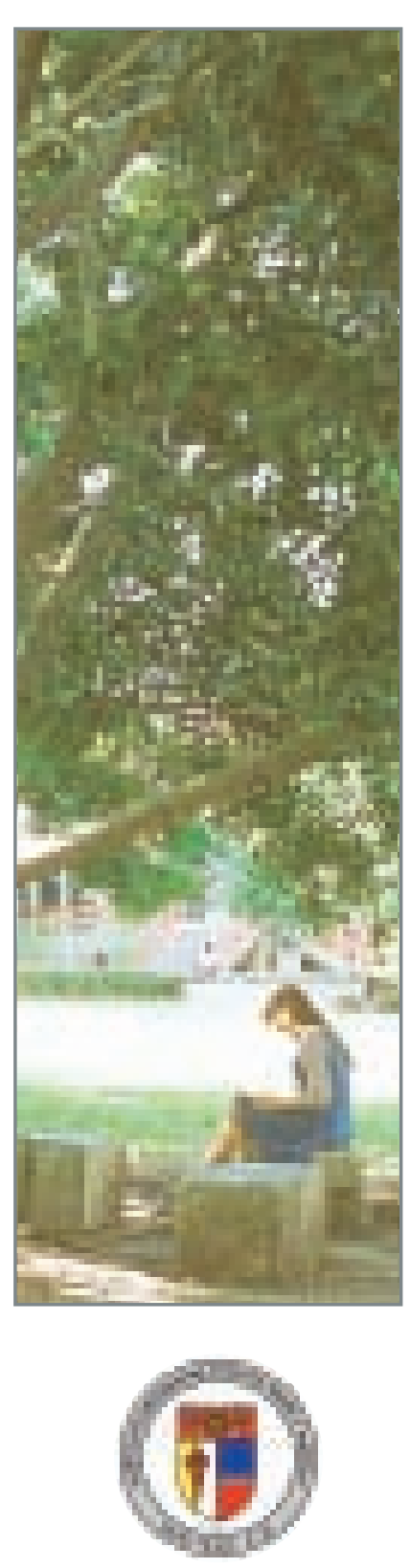